\title{
Caracterización y estudio de la fermentación espontánea del suero costeño producido en Montería
}

\author{
Characterization and study of spontaneous fermentation of \\ fermented milk product (suero costeño) produced in Monteria
}

\author{
Mónica Simanca $S,{ }^{1 *}$ Ing, Margarita Arteaga $M,{ }^{1}$ M.Sc, Yulieth Pérez $B,{ }^{2}$ Ing, \\ María Soto $Q,{ }^{2}$ Ing, Jairo Salcedo $M,{ }^{3}$ Ing.
}

\begin{abstract}
${ }^{1}$ Universidad de Córdoba, Facultad de Ciencias Agrícolas. Departamento de Ingeniería de Alimentos. A.A. 354 Montería, Colombia. ${ }^{2} E j e r c i c i o ~ p a r t i c u l a r . ~{ }^{3}$ Universidad de Sucre, Facultad de Ingeniería. Departamento de Ingeniería Agroindustrial, Sincelejo, Colombia. *Correspondencia: msimanca@sinu.unicordoba.edu.co.
\end{abstract}

Recibido: Febrero 27 de 2009; Aceptado: Diciembre15 de 2009.

\section{RESUMEN}

Objetivo. Caracterizar el proceso fermentativo del suero costeño elaborado en Montería. Materiales y métodos. Se caracterizó fisicoquímica y bromatológicamente el producto elaborado artesanalmente en Montería; se evaluó durante 24 horas la fermentación espontánea del producto elaborado en las microempresas, se determinó pH, acidez total, concentración de lactosa y mesófilos aerobios cada tres horas. Se aislaron y seleccionaron los microorganismos involucrados en la fermentación, teniendo en cuenta las propiedades de interés tecnológico y se identificaron bioquímicamente por API 50CH (BioMérieux). Resultados. El suero costeño de contenido medio en grasa, presentó una humedad de $76 \%$, extracto etéreo $(11.65 \%)$, proteína $(5.09 \%)$, lactosa $(4.36 \%)$, cenizas $(2.88 \%)$, cloruros $(2.34 \%), \mathrm{pH}(3.94)$ y acidez (1.4\% acido láctico). En la fermentación espontánea se observó un comportamiento inversamente relacionado entre el pH y la acidez, alcanzando al final del estudio un valor de 4.69 y $0.67 \%$ de ácido láctico respectivamente; se encontró un porcentaje de lactosa de $4.44 \%$ y una población de mesófilos aerobios de $2 \times 109$ UFC/mL. Se aislaron tres cepas de bacterias acido lácticas (BAL) identificadas como Enterococcus faecium y Lactobacillus brevis. Conclusiones. Las características fisicoquímicas y bromatológicas del suero costeño elaborado en la ciudad de Montería, no presentaron diferencias estadísticamente significativas entre los productos. En la fermentación espontanea hubo consumo de lactosa, aumento de la concentración de mesófilos aerobios y se presentó una relación inversa entre pH y acidez. Se aislaron e identificaron BAL con la posibilidad de ser utilizadas como cultivos iniciadores.

Palabras clave: Fermentación espontánea, bacterias lácticas, suero costeño. 


\section{ABSTRACT}

Objective. Describe the fermentation process of fermented milk product (suero costeño) produced in Monteria. Materials and methods. The fermented homemade product was characterized by physic-chemical and bromatological means. The homemade product was evaluated during 24 hours for spontaneous fermentation product, it was determined $\mathrm{pH}$, total acidity, concentration of lactose, aerobic plate counts were also done every three hours. Taking into account the properties of technological interest and identified biochemically by API $50 \mathrm{CH}$ (bioMérieux) microorganisms involved in fermentation were isolated. Results. The coastal serum medium fat content, presented a $76 \%$ moisture, ether extract $(11.65 \%)$, protein $(5.09 \%)$, lactose $(4.36 \%)$, ash $(2.88 \%)$, chloride $(2.34 \%), \mathrm{pH}(3.94)$ and heartburn (1.4\% lactic acid). In spontaneous fermentation was observed inverse relationship between $\mathrm{pH}$ and acidity at the end of the study reaching a value of 4.69 and $0.67 \%$ lactic acid, respectively. It was found $4.44 \%$ of lactose and a concentration of aerobic mesophilic bacteria of 2x109 CFU / mL. We isolated three strains of lactic acid bacteria (LAB) identified as Enterococcus faecium and Lactobacillus brevis. Conclusions. The physicochemical characteristics and qualitative homemade fermented products produced in the coastal city of Monteria, showed no statistically significant differences. The spontaneous fermentation of lactose had been consumed, increased the concentration of aerobic plate counts and presented an inverse relationship between $\mathrm{pH}$ and acidity. LAB were isolated with the possibility of being used as starter cultures. In the spontaneous fermentation of lactose there was lactose consumed, this increased the concentration of aerobic plate counts and presented an inverse relationship between $\mathrm{pH}$ and acidity. LAB were isolated with the possibility of being used as starter cultures.

Key words: Spontaneous fermentation, lactic bacteria, suero costeño.

\section{INTRODUCCIÓN}

El suero costeño es un producto lácteo, fermentado y elaborado con leche de vaca, con una consistencia viscosa espesa debido a la concentración de sólidos totales, principalmente proteína y grasa, como consecuencia de la coagulación láctica, con adición de sal (1). Este producto, típico del caribe colombiano, es el resultado de la acidificación espontánea de la leche por acción de microorganismos naturales en procesos artesanales o semiindustriales (2).

La zona típica de producción de suero costeño está localizada en la costa Caribe colombiana, especialmente en la mayoría de los municipios de los departamentos de Bolívar, Sucre, Córdoba y Cesar. También se elabora en algunos municipios de los departamentos de Santander y Norte de Santander debido a la influencia que tienen con la costa Norte (3).

La apariencia del suero costeño se caracteriza por un color blanco crema suave, relativamente fluido, presenta grumos y algo de sinéresis. Su aroma característico es moderadamente ácido y rancio con un sabor salado (3).

De acuerdo al contenido de materia grasa, según se utilice la crema separada espontáneamente durante la fermentación, se pueden distinguir tres tipos de suero costeño: de alto contenido graso, el cual está constituido por la crema retirada que lleva consigo parte del coágulo; de contenido medio en grasa, se obtiene al agregar la crema al coágulo después de la sinéresis; y de contenido bajo en grasa, al que no se agrega crema y se obtiene sólo del coágulo formado (1).

Con el aislamiento de los microorganismos involucrados en la fermentación de la leche para la producción de suero costeño en Montería, se puede obtener un fermento de mayor eficiencia, libre de contaminantes, de características 
definidas que permiten determinar las condiciones más adecuadas de fermentación para lograr un producto de mejor calidad higiénica, sensorial, nutricional y microbiológica, de menor tiempo de elaboración y con un mayor período de vida útil.

La presente investigación tuvo como objetivo caracterizar el suero costeño elaborado artesanalmente en el municipio de Montería.

\section{MATERIALES Y MÉTODOS}

Tipo de estudio y localización. La investigación se llevó a cabo en los laboratorios de Análisis de Alimentos, Microbiología de Alimentos y Lactología de la sede Berástegui de la Universidad de Córdoba, municipio de Ciénaga de Oro, ubicado a $25 \mathrm{~km}$ de la ciudad de Montería. Se realizó una investigación de tipo exploratorio descriptivo y se recolectaron muestras de suero costeño de contenido medio en grasa de seis productores del municipio de Montería, situado a 13 m.s.n.m. con precipitación anual de 1.080 $\mathrm{mm}$, temperatura promedio de $28^{\circ} \mathrm{C}$ y una humedad relativa promedio del $82 \%$.

Caracterización del suero costeño. El análisis fisicoquímico consistió en la determinación de $\mathrm{pH}$ mediante el método 945.10/90 de la A.O.A.C., adaptado y acidez total, método 950.07/90 de la A.O.A.C. adaptado; lactosa mediante el método de la antrona y cloruros (4).

El análisis bromatológico comprendió la determinación de humedad: método 930.15/ 90 de la A.O.A.C. adaptado; determinación de cenizas: método 942.05/90 de la A.O.A.C. Adaptado; determinación de extracto etéreo: método 920.39/90 de la AOAC adaptado y la determinación de proteínas total: método 955.04/90 de la AOAC adaptado, determinación macro (4).

Estudio de la fermentación espontánea. Se utilizó suero costeño de la producción artesanal de Montería y se evaluó el proceso fermentativo, midiendo variables fisicoquímicas ( $\mathrm{pH}$, acidez total y lactosa) y microbiológicas (recuento de mesófilos aerobios) (5) cada tres horas hasta completar veinticuatro, tiempo que dura la fermentación artesanalmente $(3,4)$.

Aislamiento de microorganismos involucrados en la fermentación. Se realizó la identificación de bacterias lácticas, acéticas y butíricas en el suero costeño. Las muestras se procesaron de acuerdo con la metodología planteada en el manual de técnicas y procedimientos del programa latinoamericano de microbiología e higiene de los alimentos (6).

La identificación de las bacterias lácticas se realizó utilizando el método de aislamiento directo en agar selectivo MRS (7) y en agar YMG para bacterias acéticas (8) y la técnica para los clostridios del grupo butírico de acuerdo con el medio planteado por Ingham et al (9).

Se seleccionaron las cepas que presentaron las siguientes propiedades de interés tecnológico: actividad acidificante, producción de gas y sinéresis, para la elaboración de suero costeño. Posteriormente se hicieron mezclas en proporción 1:1 entre las cepas que presentaron actividad coagulante, sinéresis y producción de gas, con el fin de realizar su identificación bioquímica.

La identificación bioquímica de las cepas escogidas se realizó en el laboratorio de microbiología especializada del departamento de microbiología de la Pontificia Universidad Javeriana (Bogotá), por medio de la bacteria de fermentación de azúcares API 50CH (BioMérieux).

Análisis estadístico. Los datos obtenidos en la caracterización del producto tradicional fueron analizados mediante estadística no paramétrica usando la prueba de KruskalWallis. En la etapa de fermentación espontánea se realizó un análisis descriptivo de las variables consideradas de importancia en el proceso fermentativo. Los procedimientos estadísticos se realizaron mediante el uso del programa estadístico SAS (System Analysis Software), versión 8.0. 


\section{RESULTADOS}

Caracterización del suero costeño. El análisis estadístico de las variables fisicoquímicas y bromatológicas del suero costeño tradicional de contenido medio en grasa se presenta en la tabla 1.

Estudio de la fermentación espontanea. Los resultados fisicoquímicos del $\mathrm{pH}$, acidez y contenido de lactosa para el estudio de la fermentación espontánea del suero costeño, se muestran en las figuras 1.

Se observó un comportamiento inversamente relacionado entre las variables $\mathrm{pH}$ y acidez durante el proceso de fermentación espontanea, alcanzando al final del tiempo de estudio un $\mathrm{pH}$ de 4.69 y una acidez de $0.67 \%$ de ácido láctico.
Durante el desarrollo de la fermentación se observó una disminución del contenido de lactosa, hasta alcanzar un valor de $4.44 \%$, la cual fue consumida por los microorganismos responsables del proceso fermentativo.

El crecimiento de los mesófilos aerobios durante las veinticuatro horas de fermentación espontanea se muestra en la figura 1 , en donde se observa un aumento de la concentración de microorganismos desde $8 \times 10^{8} \mathrm{UFC} / \mathrm{mL}$ hasta $2 \times 10^{9} \mathrm{UFC} / \mathrm{mL}$, y alcanzando un máximo a las dieciocho horas con una concentración de $3 \times 10^{9} \mathrm{UFC} / \mathrm{mL}$.

Aislamiento de microorganismos involucrados en la fermentación. Durante la fermentación del suero costeño

Tabla 1. Análisis estadístico de las variables fisicoquímicas y bromatológicas de suero costeño

\begin{tabular}{lccccc}
\hline \multicolumn{1}{c}{ Variables } & $\mathbf{n}$ & $\mathbf{X}$ & V. min. & V. max. & Coeficiente de Kruskal-Wallis \\
\hline $\mathrm{pH}$ & 6 & 3.94 & 3.52 & 4.39 & 0.1801 \\
Acidez (\% ácido láctico) & 6 & 1.40 & 0.93 & 1.85 & 0.1801 \\
Humedad (\%) & 6 & 76.03 & 73.48 & 78.43 & 0.6514 \\
Proteína (\%) & 6 & 5.09 & 4.00 & 6.00 & 0.1732 \\
Extracto etero (\%) & 6 & 11.65 & 8.93 & 14.33 & 0.3679 \\
Cenizas (\%) & 6 & 2.88 & 2.53 & 3.31 & 0.1230 \\
Lactosa $(\%)$ & 6 & 4.36 & 3.75 & 5.32 & 0.3679 \\
Cloruros $(\% \mathrm{NaCl})$ & 6 & 2.34 & 1.79 & 2.95 & 0.1561 \\
\hline
\end{tabular}

Significancia estadística $(p<0.05)$

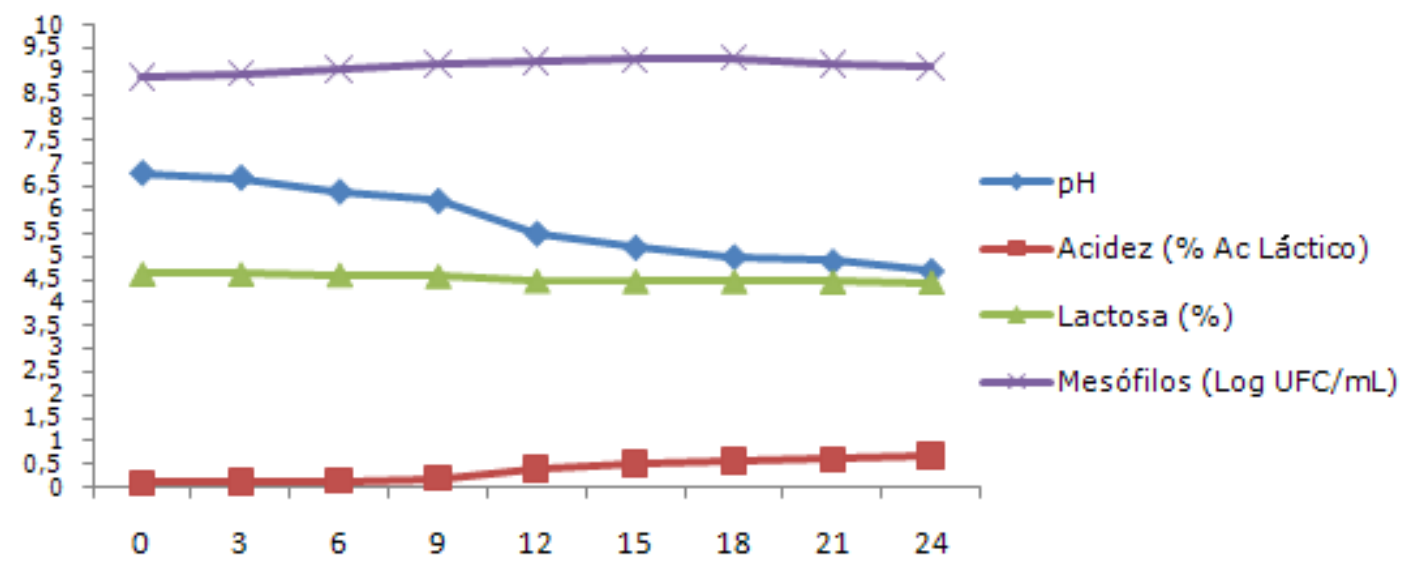

Figura 1. Seguimiento de la fermentación espontánea. 
no se observó crecimiento de bacterias acéticas, y sólo se presentó crecimiento de los clostridios del grupo butírico durante las primeras seis horas de fermentación.

En el medio para identificación de bacterias lácticas se aislaron nueve cepas, seis cocos y tres bacilos, Gram positivos y catalasa negativa (10). La morfología de las colonias del grupo cocoide fue redonda, lisa, de borde definido y color blanco, con la excepción de una cepa (denominada $\mathrm{C}_{4}$ ) cuyas colonias poseían una apariencia translúcida. Por otro lado, los lactobacilos mostraron diferencias macro y microscópicas, las colonias de la cepa $L_{1}$ se observaron rugosas y de borde irregular con lóbulos no simétricos, y microscópicamente se presentó como un bacilo robusto con gránulos metacromáticos; las colonias de las cepas $\mathrm{L}_{2}$ y $\mathrm{L}_{3}$ eran pequeñas, blancas, lisas, $\mathrm{y}$ al microscopio se presentaron como bacilos delgados y la cepa $L_{3}$ microscópicamente se agrupaba formando largas cadenas.

En el tabla 2 se muestran las propiedades de interés tecnológico de cada una de las cepas evaluadas a las 24 horas después de ser inoculadas en leche.

Se observó que sólo la cepa $\mathrm{C}_{4}$ produjo actividad coagulante, sinéresis y producción de gas, propiedades útiles en la producción de suero; sin embargo, el desuerado se dificultó por la ascensión incompleta del coágulo y porque el producto no presentó la acidez ni el aroma característico, lo que confirma el crecimiento simbiótico con otro microorganismo. Para lo cual, se obtuvieron las propiedades de interés tecnológico entre mezclas de las cepas encontradas en proporción $1: 1$, como se muestra en la tabla 3

Con la mezcla ente la cepa $\mathrm{C}_{4}$ y la $\mathrm{C}_{1}$ se obtuvo el coágulo más similar al del proceso tradicional en cuanto a firmeza y aroma, sin embargo, el coágulo no ascendió completamente hasta la superficie debido a que el dióxido de carbono producido fue insuficiente para disminuir su densidad; por lo que se decidió ensayar con un fermento conformado por las cepas $\mathrm{C}_{4}, \mathrm{C}_{1}$ y cada uno de los lactobacilos aislados $\left(L_{1}, L_{2}\right.$ y $L_{3}$ ) en proporción 1:1:1, por su producción de gas y capacidad acidificantes.

En la tabla 4 se observan los resultados de las mezclas de las cepas $\mathrm{C}_{4}$ y $\mathrm{C}_{1}$ con cada uno de los lactobacilos aislados.

Las cepas que finalmente se seleccionaron para su identificación bioquímica en el laboratorio de microbiología especializada del departamento de microbiología de la Pontificia Universidad Javeriana (Bogotá), fueron la $\mathrm{C}_{1}, \mathrm{C}_{4}$ y $\mathrm{L}_{1}$; las cuales fueron identificadas como Enterococcus faecium las

Tabla 2. Propiedades de interés tecnológico de las cepas aisladas.

\begin{tabular}{cccccccc}
\hline Cepas & $\begin{array}{c}\text { Intervalo de } \\
\text { aislamiento } \\
\text { (horas) }\end{array}$ & $\begin{array}{c}\text { acidificante en el } \\
\text { suero costeño }\end{array}$ & $\begin{array}{c}\text { Actividad } \\
\text { Actividad } \\
\text { coagulante }\end{array}$ & Sinéresis $\begin{array}{c}\text { Producción } \\
\text { de gas }\end{array}$ & Aroma \\
\cline { 3 - 7 } $\mathrm{C}_{1}$ & $0-24$ & 5.9 & 0.24 & - & - & - & Ligeramente dulce \\
$\mathrm{C}_{2}$ & $0-15$ & 4.63 & 0.73 & - & - & - & Ligeramente ácido \\
$\mathrm{C}_{3}$ & $0-15$ & 5.32 & 0.49 & - & - & - & Dulce \\
$\mathrm{C}_{4}$ & $0-18$ & 6.13 & 0.18 & + & + & + & Ligeramente ácido \\
$\mathrm{C}_{5}$ & $0-12$ & 5.41 & 0.49 & - & - & - & Ligeramente dulce \\
$\mathrm{C}_{5}$ & $0-12$ & 6.28 & 0.16 & - & - & - & Ligeramente dulce \\
$\mathrm{L}_{1}$ & $18-24$ & 6.2 & 0.15 & - & - & + & Ninguno \\
$\mathrm{L}_{2}$ & $15-21$ & 6.17 & 0.18 & - & - & - & Ninguno \\
$\mathrm{L}_{3}$ & $15-21$ & 6.23 & 0.15 & - & - & - & Ninguno \\
\hline
\end{tabular}


Simanca - Caracterización y estudio de la fermentacíon del suero costeño

Tabla 3. Propiedades de interés tecnológico de las cepas mezcladas

\begin{tabular}{|c|c|c|c|c|c|c|}
\hline \multirow{2}{*}{$\begin{array}{l}\text { Mezcla de } \\
\text { cepas }\end{array}$} & \multicolumn{2}{|c|}{$\begin{array}{l}\text { Actividad } \\
\text { acidificante }\end{array}$} & \multirow{2}{*}{$\begin{array}{l}\text { Actividad } \\
\text { coagulante }\end{array}$} & \multirow{2}{*}{$\begin{array}{c}\text { Sinéresis } \\
\%\end{array}$} & \multirow{2}{*}{$\begin{array}{c}\text { Producción } \\
\text { de gas }\end{array}$} & \multirow{2}{*}{ Aroma } \\
\hline & pH & Acidez & & & & \\
\hline$C_{4}-C_{1}$ & 4.21 & 0.72 & Coágulo firme & $>50$ & ++ & Ácido \\
\hline$C_{4}-C_{2}$ & 5.11 & 0.47 & Coágulo débil & $<50$ & ++ & Ligeramente dulce \\
\hline$C_{4}-C_{3}$ & 4.05 & 1.1 & Coágulo firme & $<25$ & + & Dulce (yogur) \\
\hline$C_{4}-C_{5}$ & 5.43 & 0.42 & Coágulo muy débil & $<50$ & ++ & Ligeramente dulce \\
\hline $\mathrm{C}_{4}-\mathrm{C}_{5}$ & 5.29 & 0.49 & Coágulo muy débil & $<50$ & ++ & Ligeramente dulce \\
\hline$C_{4}-L_{1}$ & 4.98 & 0.58 & Coágulo débil & $<50$ & ++++ & Ligeramente ácido \\
\hline$C_{4}-L_{2}$ & 5.08 & 0.53 & Coágulo débil & $<50$ & ++ & Ligeramente ácido \\
\hline$C_{4}-L_{3}$ & 5.1 & 0.51 & Coágulo débil & $<50$ & - & Ligeramente ácido \\
\hline
\end{tabular}

Tabla 4. Propiedades de interés tecnológico de las mezcladas finales

\begin{tabular}{|c|c|c|c|c|c|c|}
\hline \multirow{2}{*}{$\begin{array}{c}\text { Mezcla de } \\
\text { cepas }\end{array}$} & \multicolumn{2}{|c|}{$\begin{array}{c}\text { Actividad } \\
\text { acidificante }\end{array}$} & \multirow{2}{*}{ Actividad coagulante } & \multirow{2}{*}{ Sinéresis } & \multirow{2}{*}{$\begin{array}{c}\text { Producción } \\
\text { de gas }\end{array}$} & \multirow{2}{*}{ Aroma } \\
\hline & pH & Acidez & & & & \\
\hline$C_{4}-C_{1}-L_{1}$ & 4.5 & 0.8 & Coágulo firme & $>50 \%$ & Abundante & Acido \\
\hline$C_{4}-C_{1}-L_{2}$ & 4.6 & 0.72 & Coágulo medianamente firme & $<50 \%$ & Moderada & $\begin{array}{l}\text { Ligeramente } \\
\text { ácido }\end{array}$ \\
\hline$C_{4}-C_{1}-L_{3}$ & 5.05 & 0.52 & Coágulo medianamente firme & $<50 \%$ & Moderada & $\begin{array}{l}\text { Ligeramente } \\
\text { ácido }\end{array}$ \\
\hline
\end{tabular}

dos primeras y Lactobacillus brevis respectivamente.

Las características morfológicas macroscópicas de los microorganismos identificados se muestran en la figura 2. La identificación bioquímica de las cepas $\mathrm{C}_{1} \mathrm{y}$ $\mathrm{C}_{4}$ las incluye en el mismo género y especie, sin embargo, las características observadas mostraron diferencias morfológicas (macro y microscópicas) y fisiológicas.
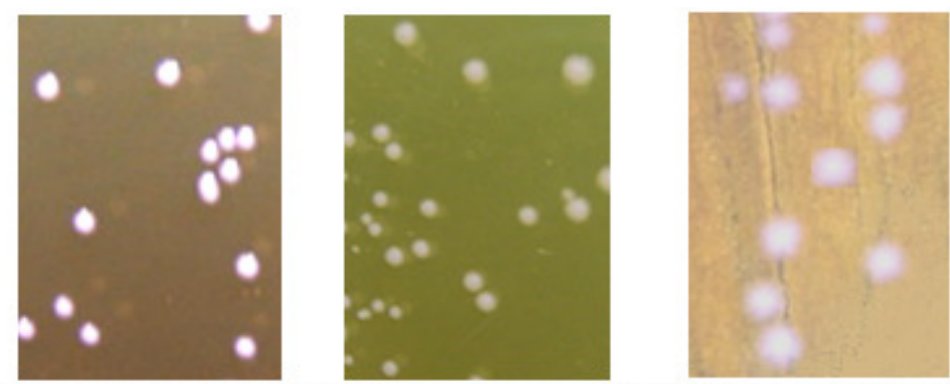

$\mathrm{C}_{1}$ Enterococcus faecium $\mathrm{C}_{4}$ Enterococus faecium $\mathrm{L}_{1}$ Lactobacillus brevis

Figura 2. Características morfológicas macroscópicas de los microorganismos aislados del suero costeño a partir de agar MRS a las 24 horas de incubación. 


\section{DISCUSIÓN}

Caracterización del suero costeño. De acuerdo con la prueba no paramétrica de Kruskal-Wallis no existe diferencia significativa entre las muestras, lo que indica que la variabilidad en los procesos de elaboración de suero costeño de contenido medio en grasa en los sitios de producción estudiados no influye en la composición fisicoquímica del mismo.

La humedad promedio del producto de $76 \%$ permite la concentración de principios activos como la proteína y grasa hasta 5.1 y $11.6 \%$, los cuales se encuentran en la leche en cantidades de $3.2 \%$ y $3-5 \%$ respectivamente (11). Mientras que el aumento en la acidez de la leche y la disminución del pH durante la fermentación del suero costeño desde valores de $0.16 \%$ y 6.5 hasta $1.4 \%$ y 3.9 respectivamente, le confieren a este su carácter ácido, evitando el crecimiento de microorganismos alterantes y patógenos, mejorando así la estabilidad y aumentando la vida útil del producto, así como la uniformidad del coágulo determinante de la textura del producto final (12). Estos valores son consistentes con los informados por el ICTA en 1990, en donde se reportó una humedad del $68 \%$, un $\mathrm{pH}$ de 3.68 y una acidez de $1.41 \%$ de ácido láctico.

El contenido de lactosa encontrado en el producto final fue de $4.4 \%$, cantidad considerable pese a la pérdida que ocurre por la solubilización de este azúcar en el lactosuero (en gran parte retirado durante el proceso de elaboración) y a su consumo durante la fermentación, quedando suficiente sustrato disponible para los microorganismos.

El porcentaje de cloruros de $2.3 \%$ en el suero, correspondiente a la cantidad de sal adicionada durante el proceso de elaboración y a las sales presentes naturalmente en la leche, determina junto con la acidez y los compuestos aromáticos producidos durante la fermentación, el sabor característico del suero costeño; contribuyendo a aumentar su período de conservación e inhibiendo las bacterias que no toleran estas concentraciones. Por otra parte el porcentaje de cenizas $(2.9 \%)$ incluye el contenido de cloruros en el suero $(2.3 \%)$ y el de los minerales presentes naturalmente en la leche retenidos en el coágulo después del desuerado $(0.6 \%)$, convirtiendo al suero costeño en fuente importante de minerales comparándolos con el porcentaje inicial en la leche: $0.9-1 \%(11)$.

Estudio de la fermentación espontánea. El seguimiento de la variable fisicoquímica $\mathrm{pH}$ durante la fermentación espontanea, evidenció un descenso desde 6.58 hasta 4.69 durante las veinticuatro horas de fermentación; asimismo se observó aumento en el valor de la variable acidez desde $0.13 \%$ hasta $0.67 \%$ de ácido láctico. Cabe anotar que al finalizar las veinticuatro horas de estudio del proceso fermentativo de las muestras analizadas, no se alcanzaron los valores de $\mathrm{pH}$ y acidez obtenidos en los productos caracterizados inicialmente, ni en los reportados por el ICTA en 1990, lo que sugiere la influencia de otras variables como la temperatura a la cual se lleva a cabo la fermentación o el efecto de contaminantes ambientales que hacen que el producto no sea estándar.

El consumo de la lactosa durante la fermentación hasta un porcentaje de $4.44 \%$, evidenció la disponibilidad de este sustrato para continuar el proceso fermentativo.

La disponibilidad de lactosa (4.44\%) al final de la fermentación (después de 24 horas) evidenció la continuación del proceso fermentativo del producto terminado durante el almacenamiento, si a este no se le proporciona temperaturas de refrigeración, que garantice la inactividad de las bacterias acidificantes con el posible aumento de la acidez y disminución del pH.

El aumento de la carga microbiana mesofila durante la fermentación presentó un comportamiento exponencial, con una notable variación del conteo microbiano inicial de las muestras de suero costeño sometidas a fermentación. Esto mismo reportó Cueto et al (2), lo cual depende de las diferencias en el proceso de elaboración entre los productores del mismo, debido a la falta de estandarización del producto. Cabe destacar que desde el inicio del estudio el 
valor reportado de microorganismos mesofilos $\left(8 \times 10^{8} \mathrm{UFC} / \mathrm{mL}\right)$ fue superior al reportado por Pérez y Soto (3) en muestras de suero costeño tradicional en Córdoba, y el cual era de $\left(6 \times 10^{5} \mathrm{UFC} / \mathrm{mL}\right)$ y al reportado por Cueto et al (2), en muestras de suero costeño obtenido en Valledupar, las que presentaron un conteo entre $9 \times 10^{1} \mathrm{y}$ $1 \times 10^{5} \mathrm{UFC} / \mathrm{mL}$.

La separación de fases para las muestras analizadas se registró entre las 18-20 horas, tiempo en el cual disminuyó el pH, aumentó la acidez, la concentración de lactosa y el descenso en la concentración de la carga microbiana mesófila. Aislamiento de microorganísmos
involucrados en la fermentación. Durante la fermentación del suero costeño no se observó crecimiento de bacterias acéticas, lo que descarta la participación de estos microorganismos en dicho proceso. Por otra parte, la abundante formación de gas en los medios para identificación de los clostridios del grupo butírico, sólo en las primeras 6 horas de fermentación, confirma su presencia como contaminante de la leche y no un agente importante en la fermentación del suero.

En la caracterización de las bacterias ácido lácticas del suero costeño producido en Valledupar, Cueto et al (2), encontraron que los recuentos de levaduras y enterobacterias se incrementaron durante las primeras horas de la fermentación, el cual es superado en las etapas finales por el predominio de BAL, posiblemente debido a la inhibición por competencia y por el efecto antimicrobiano producido como resultado del metabolismo de las BAL, incluyendo el ácido láctico y otras sustancias antimicrobianas. Resultados similares encontraron Ben Omar y Ampe (13) y Wacher et al (14) en el estudio de la carga microbiana de las fermentaciones del pozol, una bebida fermentada a base de cacao y maíz de origen mesoamericano muy popular al sur de México.

El grupo microbiano predominante en el proceso fermentativo del suero costeño fueron las $B A L$, en donde se obtuvieron nueve cepas diferentes, seis con morfología cocoide y tres bacilar; de las cuales tres presentaron las características de interés tecnológico para la elaboración del producto en mención (actividad acidificante, coagulante, sinéres y producción de gas) y basados en el API $50 \mathrm{CH}$ fueron identificadas como Enterococcus faecium (dos cepas) y Lactobacillus brevis. Este tipo de bacterias son comúnmente asociadas con las fermentaciones en las regiones cálidas de clima tropical o subtropical (15), como el que se presenta en la costa Caribe colombiana (2).

Resultados similares encontraron Cueto et al (2) en el suero costeño elaborado en la ciudad de Valledupar, en donde reportaron once especies diferentes de BAL, la mayoría de las cuales son frecuentes en productos lácteos fermentados (Lactobacillus plantarum, Lactobacillus paracasei, Lactococcus lactis) y otras especies reportadas en cantidades menores como Leuconostoc mesenteroides, Lactobacillus brevis y Lactobacillus acidophilus. Por otra parte, Rashid et al (16) identificaron Enterococcus faecium entre las BAL aisladas de la leche fermentada tradicional de Dahi en Bangladesh.

En una gran variedad de productos lácteos fermentados se ha caracterizado e identificado la carga microbiana responsable del proceso fermentativo como perteneciente al grupo de $\mathrm{BAL}$, tal como lo señala Savadogo et al (15) en la leche fermentada tradicional de Fulani en Burkina Faso (África occidental), Chammas et al (17) en la leche fermentada del Líbano y Schillinger et al (18) en productos lácteos fermentados en Kenya.

En la fermentación espontanea se observó un comportamiento inversamente relacionado entre las variables $\mathrm{pH}$ y acidez, una disminución del contenido de lactosa y un aumento de la concentración de microorganismos mesofilos.

Durante la fermentación del suero costeño no se observó crecimiento de bacterias acéticas, y solo se presentó crecimiento de los clostridios del grupo butírico durante las primeras seis horas de fermentación. 
El grupo microbiano predominante en el proceso fermentativo del suero costeño fueron las BAL (Enterococcus faecium y Lactobacillus brevis), las cuales presentaron las características de interés tecnológico para la elaboración del producto.
En conclusión, La caracterización del suero costeño de contenido medio en grasa en la ciudad de Montería, no presentó diferencias estadísticamente significativas entre los seis productores, indicando que la variación en el proceso de elaboración no influye en su composición.

\section{REFERENCIAS}

1. Instituto de Ciencia y Tecnología de alimentos (ICTA) - Universidad Nacional de Colombia. Programa andino de desarrollo tecnológico para el medio rural: Manual de elaboración de productos lácteos fermentados. Bogotá, Colombia. 1990.

2. Cueto C, García D, Garcés F, Cruz J. Preliminary studies on the microbiological characterization of lactic acid bacteria in suero costeño, a Colombian traditional fermented milk product. Rev Latinoam Microbiol 2007; $49(1,2): 12-18$.

3. Pérez $Y$, Soto $M$. Evaluación de la etapa de fermentación espontánea del suero costeño y aislamiento de los microorganismos involucrados en dicha etapa. [Tesis de pregrado]. Montería: Universidad de Córdoba, Facultad de Ciencias Agrícolas, Departamento de Ingeniería de Alimentos; 2004.

4. Simanca, M, Arteaga, M, Pérez, Y, Soto, M y Salcedo, Jairo. Caracterización de un producto lácteo fermentado "suero costeño" obtenido a partir de fermentaciones inducida con bacterias acido lácticas. In: Memorias del VI Congreso Iberoamericano de Ingeniería de alimentos. CIBIA VI: 2007; 16(2). 147: 149.

5. Instituto de vigilancia de medicamentos y alimentos (INVIMA). Manual de técnicas de análisis para control de calidad microbiológica de alimentos para consumo humano: División laboratorio de alimentos y bebidas alcohólicas, sección de microbiología de alimentos. Bogotá: INVIMA; 1998.
6. Escobar M. Programa latinoamericano de microbiología e higiene de los alimentos: manual de procedimientos. Medellín: Universidad de Antioquia, Facultad Nacional de Salud pública, Departamento de Ciencias Especificas; 1994.

7. IDF. Dairy starer cultures of lactic acid bacteria (LAB)-standard of identity Standard 149A. Brussels: IDF; 1997.

8. Du Toit W, Lambrechts $M$. The enumeration and identification of acetic acid bacteria from South African red wine fermentations. Int J Food Microbiol 2002; 74: 57-64.

9. Ingham S, Hassler J, Tsai Y, Ingham B. Differentiation of lactatefermenting, gas-producing Clostridium spp. isolated from milk. Int J Food Microbiol 1998; 43: 173-183.

10. Rossetti L, Giraffa G. Rapid identification of dairy lactic acid bacteria by M13-generated, RAPD-PCR fingerprint databases. J Microbiol Methods 2005; 63: 135-144.

11. Casado C, García J. La composición de la leche y los factores que la influyen. Madrid: Ayala: 1999.

12. Messens $W$, De Vuyst L. Inhibitory substances produced by Lactobacilli isolated from sourdoughs-a review. Int J Food Microbiol 2002; 72: 31-43. 
13. Ben Omar N, Ampem F. Microbial Community Dynamics during Production of the Mexican Fermented Maize Dough Pozol. Appl Environ Microbiol 2000; 66: 3664-3673.

14. Wacher $C$, Cañas A, Bárzana E, Lappe $P$, Ulloa M, Owens J. Microbiology of Indian and Mestizo pozol fermentations. Food Microbiol 2000; 17: $251-256$.

15. Savadogo A, Ouattara C, Savadogo P, Ouattara A, Barro N, Traore A. Microorganisms Involved in Fulani Traditional Fermented Milk in Burkina Faso. Pak J Nutr 2004; 3(2): 134-139.

16. Rashid M, Togo K, Ueda M, Miyamoto T. Identification and characterization of dominant lactic acid bacteria isolated from traditional fermented milk Dahi in Bangladesh. World J Microbiol Biotechnol 2007; 23 (1): 125-133.
17. Chammas G, Saliba R, Corrieu G, Béal C. Characterisation of lactic acid bacteria isolated from fermented milk "laban". Int J Food Microbiol 2006; 110 (1): 52-61.

18. Schillinger U, Mbugua S, Holzapfel W, Mathara J, Kutima P. Isolation. identification and characterisation of the dominant microorganisms of kule naoto: the Maasai traditional fermented milk in Kenya. Int J Food Microbiol 2004; 94 (3): 269-278. 